\title{
Los primeros viajes audiovisuales (1936) de Rolf Blomberg en Ecuador
}

The first audio-visual journeys (1936) of Rolf Blomberg in Ecuador

Franco Passarelli ${ }^{1}$

fpassarelli16@gmail.com

\section{Resumen}

El objetivo del presente artículo es indagar, a partir del análisis comparativo de los filmes "En Canoa a la Tierra de los Reductores de Cabezas" y "Vikingos en las Islas de las Tortugas Gigantes" de Rolf David Blomberg (Suecia, 1912- Ecuador, 1996), la producción y reproducción de imágenes de exploradores europeos en Ecuador durante la época de entre-guerras (1919-1939). El trabajo se centra principalmente en el análisis de la forma fílmica de ambas películas donde se pretende poner en discusión la construcción de "viajes audiovisuales". Tiempo, espacio y sujeto quedan desajustados en diferentes niveles como conclusiones del análisis comparativo. Las preguntas que van a guiar este trabajo son ¿Qué tipo de narrativas e imaginarios construyeron los "viajes audiovisuales" de los exploradores/realizadores europeos en Ecuador? ¿Cómo circulaban esas ideas? ¿Cuál es la importancia de estudiar las imágenes- movimiento de este tipo de exploradores/realizadores desde y para la Antropología Audiovisual?

\section{Palabras clave}

Rolf Blomberg, viajes audiovisuales, crónica de exploradores, representación, antropología audiovisual.

Forma sugerida de citar: $\quad$ Passarelli, Franco (2017). Los primeros viajes audiovisuales (1936) de Rolf Blomberg en Ecuador. Univeristas, XV(27), pp. 117-135.

1 FLACSO- Ecuador. Orcid: 0000-0002-3582-8102. 


\begin{abstract}
The objective of this article is to investigate, from the comparative analysis of the films "In Canoe to the Land of the Reductors of Heads" and "Vikings in the Islands of the Giant Tortoises" of Rolf David Blomberg (Sweden, 1912- Ecuador, 1996), the production and reproduction of images of European explorers in Ecuador during the interwar period (1919-1939). The work is mainly focused on the analysis of the film form of both films where the construction of "audio-visual trips" is intended to be discussed. Time, space and subject are left unadjusted at different levels as conclusions of comparative analysis. The questions that will guide this work are: What kind of narratives and imaginaries constructed the "audiovisual journeys" of European explorers / filmmakers in Ecuador? How did these ideas circulate? What is the importance of studying the movement images of this type of explorers / directors from and for Audiovisual Anthropology?
\end{abstract}

Keywords

Rolf Blomberg, audiovisual journeys, chronicles of explorers, representation, audiovisual anthropology.

\title{
Introducción
}

El presente trabajo propone un análisis fílmico acerca de la producción de imágenes- movimiento realizadas por exploradores europeos en Ecuador durante la época de entre-guerras (1919-1939). Las películas que se van a analizar son "En Canoa a la Tierra de los Reductores de Cabezas" (Rolf Blomberg, 1936) y "Vikingos en las Islas de las Tortugas Gigantes" (Rolf Blomberg, 1936). Ambos filmes construyen un "viaje audiovisual" (concepto propuesto por este artículo) a partir de la representación y de la narrativa, donde se destaca el desplazamiento espacial y temporal de los sujetos filmados.

Si bien este trabajo sólo se detiene en dos producciones de un mismo autor, se intenta proponer un modelo de análisis que pueda ser útil en otras investigaciones sobre exploradores e imaginarios. La metodología, extraída de los estudios principalmente de las artes audiovisuales, resulta útil para el campo de la Antropología Audiovisual ya que nos permite (re)conocer formas e imaginarios en el análisis audiovisual. La forma fílmica de una película documental/etnográfica, siempre está determinada por la mirada del realizador. Por lo tanto, el 
análisis de la misma, en la construcción de los "viajes audiovisuales", da cuenta de imaginarios visuales que se producen y reproducen a partir de las imágenes.

\section{Representaciones e imaginarios en las crónicas de exploradores en Ecuador, a principios del siglo XX}

En el período de entre-guerras (1919-1939) el Estado ecuatoriano estaba en un proceso de "modernización", por lo que los migrantes europeos como Rolf Blomberg ${ }^{2}$, Paul Rivet ${ }^{3}$, el Marqués de Wavrin ${ }^{4}$ y el padre Crespi ${ }^{5}$ eran

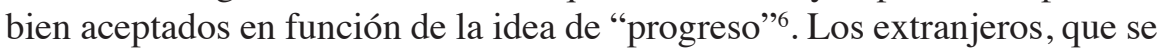
relacionaban con los grupos de poder, llegaban a buscar lo diverso, lo distinto, llevado hasta el extremo de lo exótico (Giordano y Gustavsson, 2013, p. 42). Vale aclarar que cada uno tenía su proyecto particular: Rivet hacía estudios etnográficos para contribuir a la incipiente disciplina antropológica, Crespi pretendía dar a conocer las tareas evangelizadoras en la Amazonía y Blomberg, al igual que Wavrin, buscaba el éxito comercial de sus

2 Rolf David Blomberg nació en 1912 en Estocolmo, Suecia. Llegó a Ecuador por primera vez en 1934 y luego regresó en 1936 par filmar las dos películas que son objeto de estudio de este artículo. Su perfil es de un hombre polifacético: fue naturalista, realizador audiovisual, fotógrafo, caricaturista, escritor, periodista, pero principalmente, explorador. Murió en 1996 en Ecuador.

3 Médico militar de formación, luego arqueólogo y etnógrafo francés, llegó a Ecuador en 1901 bajo la Segunda Misión Geodésica Francesa. Llevó a cabo estudios de la industria material, de lingǘstica y tecnología, alejándose de los estudios antropométricos que caracterizaban a la incipiente disciplina antropológica en ese momento. Su corriente teórica fue el difusionismo, que bajo la idea de que no hay culturas superiores ni inferiores, los cambios en ellas se deben al contacto. Paul Rivet fue uno de los creadores del Museo del Hombre de París en 1938. Además, inclinado políticamente al socialismo, fue diputado y su carrera de investigación siempre intentó ligar lo político con lo científico (Lauriére, 2010).

4 El Marqués de Wavrin fue un hombre de la nobleza belga que desde 1913 realizó expediciones por Sudamérica filmando numerosas películas. La más conocidas fueron: En el corazón de América del Sur desconocida (1925), Entre los indios hechiceros. Los indios del Gran Chaco (1925), Las cataratas del Iguazú (1925), La América exótica (1926) y Au pays du scalp (En el país de los cazadores de cabezas) (1931). Esta última fue la que tuvo mayor éxito en la época e intentaba mostrar la vida de los "Jíbaros" a partir de las reseñas que había hecho el aventurero estadounidense Fritz Up de Graff (Guarín, 2012).

5 Carlos Crespi Croci fue un sacerdote cristiano de la escuela salesiana. Nació en Italia y en 1923 llegó a Ecuador como organizador de una exposición de objetos arqueológicos. Crespi tenía el perfil de hombre polifacético, como todos los exploradores que estamos viendo: hizo estudios botánicos, faunísticos, geológicos y etnográficos. Filmó a los "Jíbaros" en sus viajes por la selva y así fue que realizó los "Los Invencibles Shuaras del Alto Amazonas" (1927), película de gran éxito en la época.

6 La incorporación de los extranjeros en la sociedad nacional ecuatoriana se dio a través de las clases medias-altas que veían con "buenos ojos" la llegada de gente europea. "Por sus orígenes y formación de clase media o alta, los viajeros compartían muchos de los supuestos de la clase terrateniente ecuatoriana que se orientaba hacia Europa" (Fitzell, 1994, p. 37). 
filmes. Si bien sus proyectos eran diferentes, su principio cognoscitivo era similar: "discutir acerca de las diferencias y similitudes que tienen las culturas indígenas respecto de la civilización occidental” (León, 2010, p. 118). En sus viajes, buscaban vivir y compartir experiencias con "otras culturas", escapando de una Europa colapsada por las guerras y desesperanzada por el destino de la humanidad. Ecuador como destino alejado y exótico, circulaba como imaginario en Europa y por lo tanto los países del Viejo Continente enviaban informantes para documentarlo.

Rolf Blomberg no era ajeno a esto y, como señala Gonzalo Vargas (2013, p. 118) él cumplirá el rol de "el nuevo explorador/colonizador europeo, quien viajará a los territorios desconocidos de la América salvaje e indómita para los ojos de Occidente (...) Estos viajes se dan en función de catalogar, clasificar y archivar..." a los diversos modos de vida, entendidos como "cultura", dentro de la Antropología y el cine. Surge el problema entonces de cómo representarlos. María Luisa Ortega (2003, p. 96), al caracterizar a estos "exploradores/colonizadores" del período de entre-guerras, afirma que la "fascinación etnográfica" sobre lo "primitivo" y lo "salvaje" es uno de los grandes componentes del proceso de producción y por lo tanto de la construcción narrativa y representativa de los viajes audiovisuales en las crónicas de los exploradores. "Pero además la suerte de taxidermia que el cine etnográfico y étnico del momento operaba sobre las culturas representadas, y que contagiaba toda obra de documental o de ficción, se enfrentaba a la representación del Otro en busca de representar sus esencias (...)" (Ortega, 2003, p. 98). Se trata entonces de deshistorizar, aplicando el modelo de "taxidermia" (seguir viendo como vivo algo que está muerto) a lo etnográfico (Rony, 1996). Por lo tanto, desde este modelo de construcción representativa, se intentan "borrar las supuestas impurezas de cambio cultural, y con ello eludir la realidad del contacto cultural, la colonización y el proceso histórico" (Morris, 1996, p. 64, en: Griffiths, 2002 , p. 305, traducción nuestra). Esto último se relaciona directamente con el modelo de "etnografía de salvataje", propuesto por James Clifford (1999), donde se entendía que las culturas "prístinas" estaban en peligro de extinción y por lo tanto había que registrarlas antes de que se pierdan.

Dicho registro debía ser mimético (Bordwell, 1996; Suhr y Willerslev, 2012), paradigma característico de principios del siglo XX. Dentro de este paradigma se piensa a la representación como copia fiel de la realidad. De esta forma, se nos hace creer que no hay diferencia entre lo que vemos en pantalla y lo que le sucedió en concreto al realizador (experiencia). El paradigma mimé- 
tico marca una relación de 1 a 1 entre representación y realidad, dando cuenta de principios positivistas en su forma de entender el mundo. En síntesis, se pensaba que el registro de las culturas en extinción, es el reflejo de la realidad.

A nivel regional, uno de los exploradores que realizó numerosas filmaciones en Latinoamérica fue el Marqués de Wavrin. Según M. L. Ortega (2003), él es un claro ejemplo de cómo estos viajeros buscaban los ritos primitivos y el salvataje de las prácticas en extinción, pero sin adoptar una postura paternalista y romántica. Sus películas fueron un gran éxito comercial y fue reconocido en todo el mundo por sus viajes. Otro extranjero que estuvo por estas tierras fue Paul Rivet, que con sus fotos, marcó una tendencia en los estudios de la época (Guarín, 2012). La fotografía antropométrica que realizó en las zonas de Tulcán, Riobamba, Saraguro y Santo Domingo se distanciaba, en parte, de los estudios positivistas que dominaban la incipiente disciplina antropológica (Troya, 2012). Los trabajos de Rivet sólo circulaban en ambientes académicos. Rivet y Wavrin eran amigos (Guarín, 2012, p. 185), lo que marca las redes de relaciones entre los exploradores y los antropólogos en esta etapa incipiente del cine documental y etnográfico.

A nivel local, si hacemos un sintético panorama de las tres obras fundacionales del cine ecuatoriano, vemos que se producen en la época recién descripta. Como bien señala León (2010, p. 93) "los primeros films rodados en el Ecuador que se conservan hasta la actualidad son también los primeros testimonios cinematográficos de los pueblos indígenas que conocemos". Según León (2010, p. 93), las primeras filmaciones en Ecuador son: 1) las que pertenecen al Fondo Miguel Ángel Álvarez (1927- 1935); 2) Los invencibles Shuaras del Alto Amazonas (1927), del padre Carlos Crespi; y 3) Ecuador (1929) de Manuel Ocaña.

\section{Los viajes audiovisuales: espacio, tiempo y sujeto desde la forma fílmica}

Llamamos "viaje audiovisual" a la construcción fílmica de un espacio y un tiempo particular, en el cual el realizador se desplaza, y donde se encuentra con un sujeto (objeto para la época) "Otro". Se trata de una puesta en forma fílmica (Bordwell y Thompson, 1993; Cook, 1994) donde las herramientas audiovisuales escogidas por el viajero/realizador nos hablan de qué era lo que buscaba y cómo lo hacía, en síntesis, de su mirada (Ardèvol, 2006). Definimos al término "forma fílmica" como la selección de herramientas 
del leguaje audiovisual que emplea el realizador: tipo de plano, movimiento de cámara, tipo de lente, punto de vista ${ }^{7}$, punto de escucha ${ }^{8}$ y montaje, entre otros. En la conjugación de estos elementos, sumado al tipo de relación que el viajero/realizador estableció con los sujetos filmados, encontramos el modo de representación del filme (Ardèvol, 2006).

La elección de cada una de las herramientas mencionadas no es azarosa, y nos "dice" mucho acerca de la postura del viajero/realizador. La selección de un tipo de encuadre (conjugado con el resto de las herramientas del lenguaje audiovisual) crea diferentes sentidos a los espectadores. Estos sentidos, por lo tanto, son parte del "contenido" del filme (Metz, 2002 [1967]). En consecuencia, entendemos la relación forma/contenido como dialéctica, donde se hacen indistinguibles los límites entre uno y otro.

\section{Las películas}

Hemos decidido tomar como objeto de estudio las dos primeras películas que ha realizado Rolf Blomberg en Ecuador, "Vikingos en las islas de las tortugas gigantes" $\mathrm{y}$ "En canoa a la tierra de los reductores de cabezas"10, ambas filmadas en 1936, por varias razones. La primera es que ambos filmes no han sido proyectadas dentro de Ecuador, debido a que fueron producidas

7 Con el término punto de vista, desde la teoría del cine, me refiero a "Un emplazamiento, real o imaginario, desde el cual se produce una representación. Es un punto desde el cual un pintor que utiliza la perspectiva lineal organiza su cuadro; y también, en el cine, el punto imaginario, eventualmente móvil, desde el cual fue filmado cada plano" (Aumont y Marie, 2006, pp. 183-184).

8 Con el término punto de escucha, también desde la teoría del cine, aludo a desde dónde es encuadrado el sonido (Chion, 2011).

9 Vikingar på sköldpaddoarna

Vikingos en las islas de las tortugas gigantes

Dirección: Rolf Blomberg

Formato: $35 \mathrm{~mm}$

Duración: 10'25"

Año: 1936

Locación: Galápagos, Ecuador

(Fuente: Archivo Blomberg)

10 I kanot till huvudjägarnas land

En canoa a la tierra de los reductores de cabezas

Dirección: Rolf Blomberg

Formato: $35 \mathrm{~mm}$

Duración: 12' 5',

Año: 1936/ Locación: Amazonía, Ecuador (Fuente: Archivo Blomberg) 
exclusivamente para el público sueco, por lo que este artículo intenta rescatarlas del olvido. La segunda es con el fin de ver, cómo se insertaban este tipo exploradores en el "mundo" de los viajeros. Por último, poner el foco en ambas películas nos permite ir llenando de a poco el vacío que existe sobre la historia del documental etnográfico ecuatoriano, dando a conocer nuevos referentes que sean objeto de análisis de futuras investigaciones tanto en Antropología como en Antropología Audiovisual y en Artes Audiovisuales.

La primera película, realizada en las Islas Galápagos, narra cómo viven los inmigrantes nórdicos en un contexto "extraño". El realizador focaliza en las distintas familias (noruegas, suecas e islandesas) que viven en las Islas y que sirven como eje articulador de la película para narrar cómo es la vida allí. El filme muestra las actividades cotidianas de los lugareños, cómo recolectan frutos y raíces de las plantas, cómo producen azúcar de la caña y cómo cazan animales. A partir de esta construcción de la cotidianidad el realizador intenta demostrar que las familias son autosuficientes en el "extraño" paisaje de las Islas.

La segunda, describe el modo de vida "jíbaro" (hoy shuar) y se centra en la tzanza (cabeza reducida). El personaje principal de la película es Henry Nielsen, un aventurero danés que se dirige con un equipo de exploración a las "tierras jíbaras". La película muestra las actividades cotidianas de la comunidad indígena, donde aparecen la preparación de la chicha, la caza con cerbatana y la fabricación de artesanías. Además, hay momentos donde aparece el contacto entre Henry Nielsen y la comunidad, a través de los festines e intercambios de objetos. En esta película el relato se inicia con los preparativos del viaje a la comunidad selvática, principalmente con la fabricación de la canoa. La travesía hacia el destino (la comunidad jíbara) es dificultoso y dramático. El final de la película tiene la misma construcción narrativa.

\section{Análisis comparativo: la construcción del viaje audiovisual en ambas películas}

Al establecer una comparación en la construcción de los viajes audiovisuales de las películas "Vikingos en las islas de las tortugas gigantes" (1936) y "En canoa a la tierra de los reductores de cabezas" (1936), encontramos similitudes y diferencias. A continuación vamos a desarrollar sintéticamente los puntos en común:

El eje formal que utiliza Blomberg en ambas películas es la construcción de mini-secuencias. Por el lado de "En Canoa..." cada una de las mini-secuen- 
cias (que se corresponden con las escenas) narran diferentes actividades de la comunidad, que tienen que ver con la preparación de los alimentos, con la fabricación de armas y cerámica, con los juegos, con los animales, los niños y los intercambios de objetos. En la mayor parte de las escenas aparece la figura de Henry Nielsen como disparador de situaciones, lo cual es un rasgo de interactividad (catalización de una situación a partir de la puesta de cámara). Ejemplo de ello es cuando él le enseña la cámara de fotos a los niños (ver Figura 1), o cuando le indica a un joven que dispare con la cerbatana. La construcción de mini-secuencias, atravesadas por Henry Nielsen en su relación con la comunidad, es el eje formal de la película. Del mencionado eje de análisis distinguimos sub-ejes que lo sostienen: la construcción del viaje dramático, el retrato del modo de vida, lo lúdico, la interactividad, los planos generales y fijos, la descripción de la voz en off, la lucha del Hombre contra la Naturaleza.

\section{Figura 1}

\section{Henry Nielsen muestra la cámara a los niños}

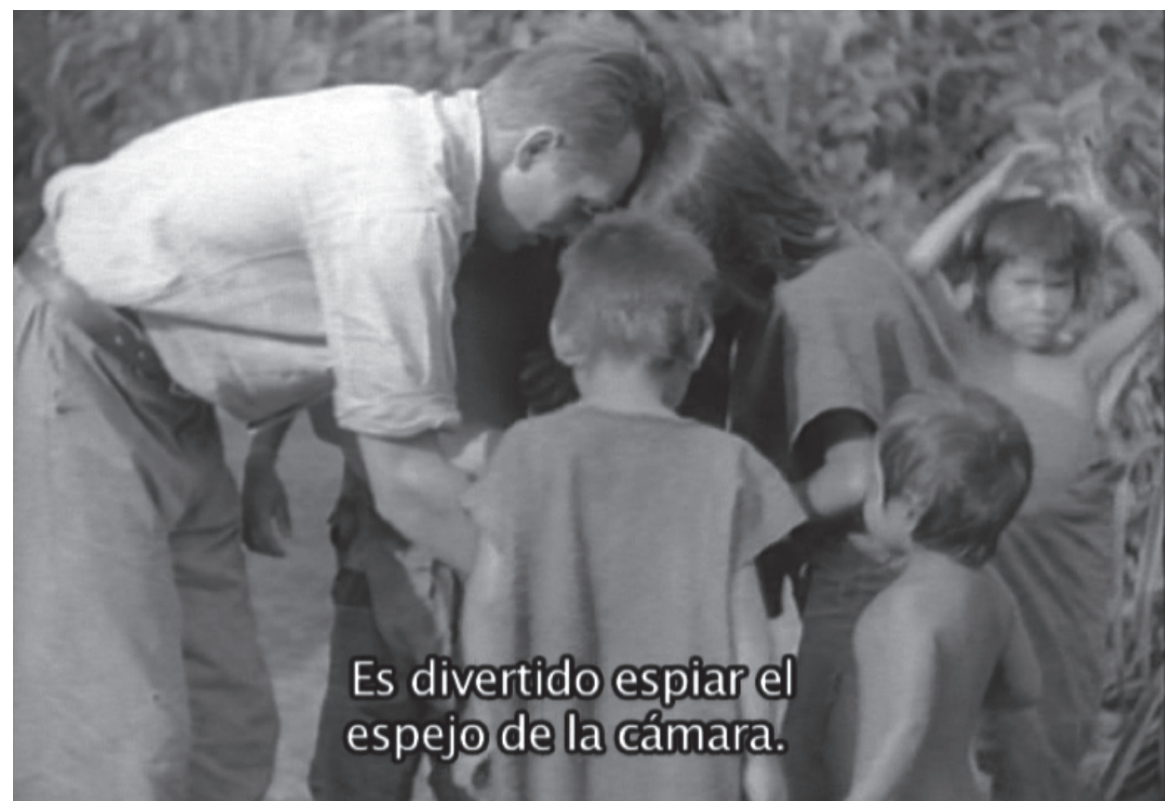

Por el lado de la película "Vikingos...", Blomberg sigue manteniendo como eje formal la construcción de mini-secuencias. Cada una de ellas narra 
diferentes situaciones cotidianas de subsistencia de los colonos en las islas: la cacería, la recolección, la fabricación de azúcar, entre otras. En este sentido, la película se basa en la lucha cotidiana de los colonos nórdicos por subsistir ante un ambiente hostil. A partir del mencionado eje formal, Blomberg segmentó a la película según las actividades, pero también según las familias. Por un lado nos muestra a los Lundberg, por otro a los Stampa y por otro, brevemente esbozado, a los Worm-Muller. De este eje formal se disparan los mismos subejes que sustentan al anterior filme, ellos son: la lucha del Hombre contra la Naturaleza, la utilización de planos generales y fijos, descripción con la voz en off de lo que sucede en la imagen, interactividad, nombres y formas de aprendizaje familiar, narrativa clásica y retrato del modo de vida.

Ambas películas apuntan a retratar el modo de vida de la comunidad desde la observación: los shuar por un lado y los colonos nórdicos por el otro. A partir de filmar situaciones donde la gente del lugar realiza actividades, en su mayoría económicas, Blomberg intenta acercase a la cotidianidad de esas situaciones. Ambos filmes tienen en general características del modo de representación expositivo (Ardèvol, 2006; Nichols, 1997): voz en off del realizador, gran cantidad de planos generales y fijos, autoridad marcada en el realizador, no hay una revelación del dispositivo de filmación y la cámara muchas veces permanece oculta. Sin embargo hay un componente de performatividad (evidencia de la actuación) al hacer posar a los personajes frente a la cámara (ver Figuras 2 y 3 ).

También, ambas películas se corresponden plenamente con el canon de representación del paradigma mimético. Los movimientos de la cámara intentan ser imperceptibles, la altura de la cámara está elevada a la altura del nivel de los ojos, el montaje pretende ser "invisible" y el espacio debe ser continuo y uniforme. La construcción narrativa clásica a partir de la continuidad del montaje, de la estructura (de introducción, problema, y desenlace) y el desarrollo de los personajes, la podemos ver también en ambas películas. Sin embargo lo utilizan de diferentes formas como veremos en las diferencias.

Las dos películas usan el tono lúdico, la vanalización y desproblematización de las situaciones. Esto se da especialmente desde la voz de Blomberg pero también desde la musicalización. Se intenta desde el humor que el espectador establezca una relación de empatía con el "Otro". A la vez, lo lúdico contribuye al ritmo fílmico de la película, liberándola sólo del carácter informativo. Con esto último nos referimos a que no todo es información directa, sino que Blomberg utiliza pequeñas secuencias cómicas para darle "aire" al espectador. 


\section{Figura 2}

Chumbela, líder de la comunidad, toma chicha mientras mira a la cámara. Fotograma extraído de "En Canoa a la Tierra de los Reductores de Cabezas"

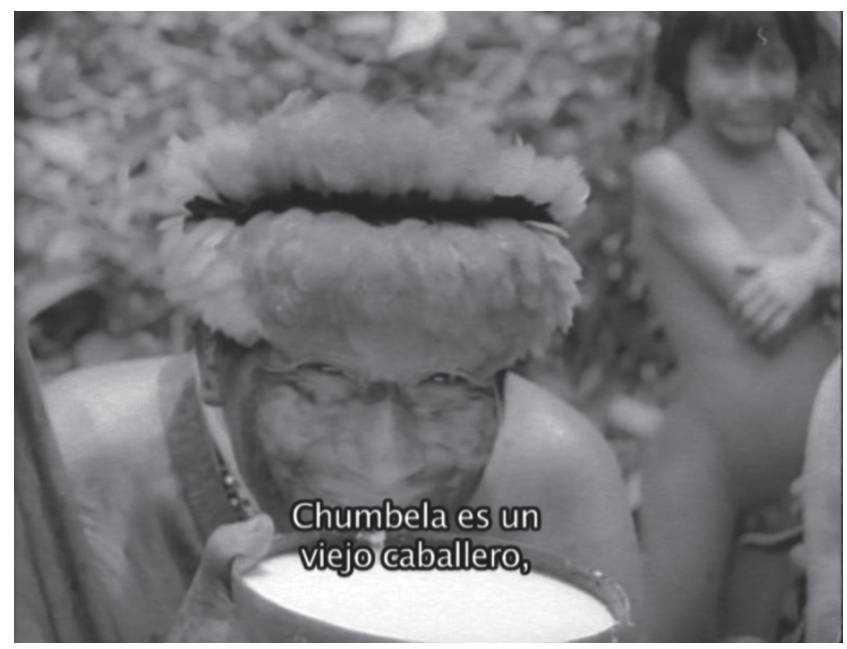

\section{Figura 3}

Arthur Worm-Muller, colono escandinavo, muestra el árbol de papaya mirando a la cámara. Fotograma extraído de "Vikingos en las Islas de la Tortugas Gigantes"

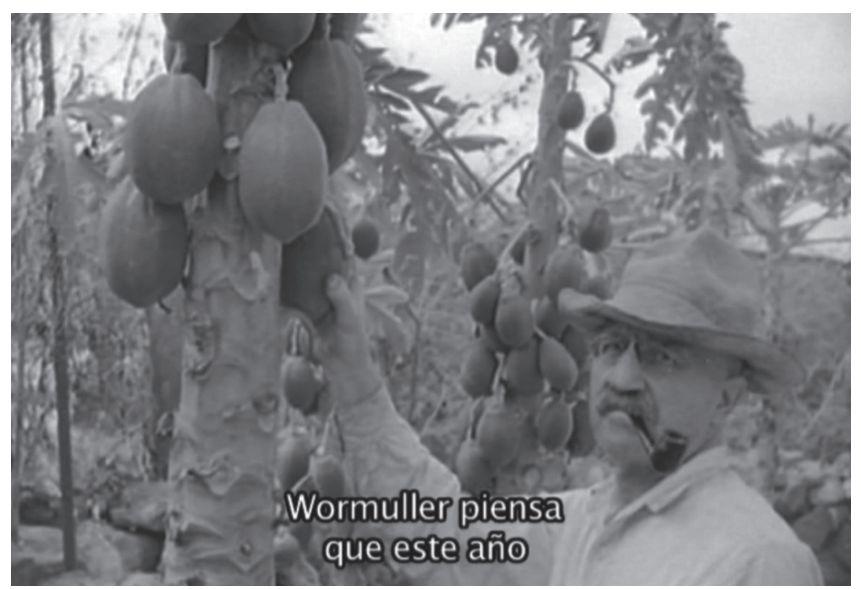


Las diferencias que encontramos entre ambas películas son:

Una de las diferencias que vemos es el punto de vista de la cámara. En "En canoa..." muchas de las situaciones están filmadas con una angulación picada, mientras que en "Vikingos..." la mayoría de los acercamientos Blomberg los hace al nivel de los ojos. Poner la cámara al nivel de los ojos nos da una relación de horizontalidad con el que estamos filmando, ponerla por encima de él, es un signo de autoridad (ver Figuras 4 y 5).

\section{Figura 4 \\ Plano picado. Fotograma extraído de "En Canoa a la Tierra de los Reductores de Cabezas"}

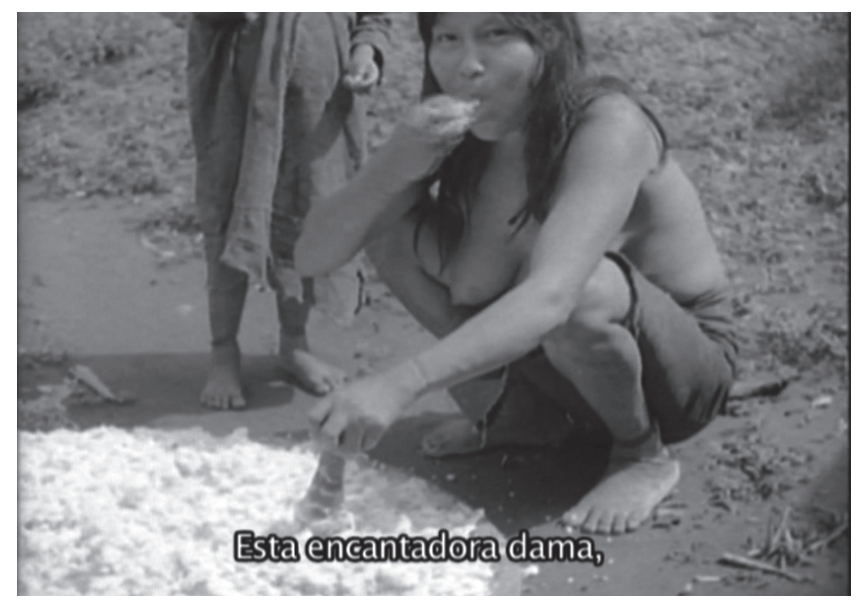

Otra de las cuestiones que aparece en la película "Vikingos..." y en "En canoa..." no, es la enseñanza familiar y las relaciones intergeneracionales. En la primera película, muchas de las actividades que muestra, son realizadas por toda la familia. En la segunda, la mayoría de los personajes están solos. En la primera se destaca lo colectivo, en la segunda lo individual. Sin embargo, a pesar de marcar lo colectivo en "Vikingos...", hay una individualización de los personajes a partir de darles un nombre (ver Figura 3 y Figura 5). Blomberg presenta a los personajes individualmente (Lundberg, Stampa, Worm-Muller, Finssen), mientras que en "En canoa..." solo vemos una masa indistinguida de gente, rasgo típico del modo expositivo de representación. Sólo al que reconoce Blomberg en "En canoa..." es al jefe de la comunidad, llamado Chumbela (ver Figura 2). El resto de las personas no tiene nombre. 


\section{Figura 5 \\ Plano contrapicado. Fotograma extraído de "Vikingos en las Islas de la Tortugas Gigantes"}

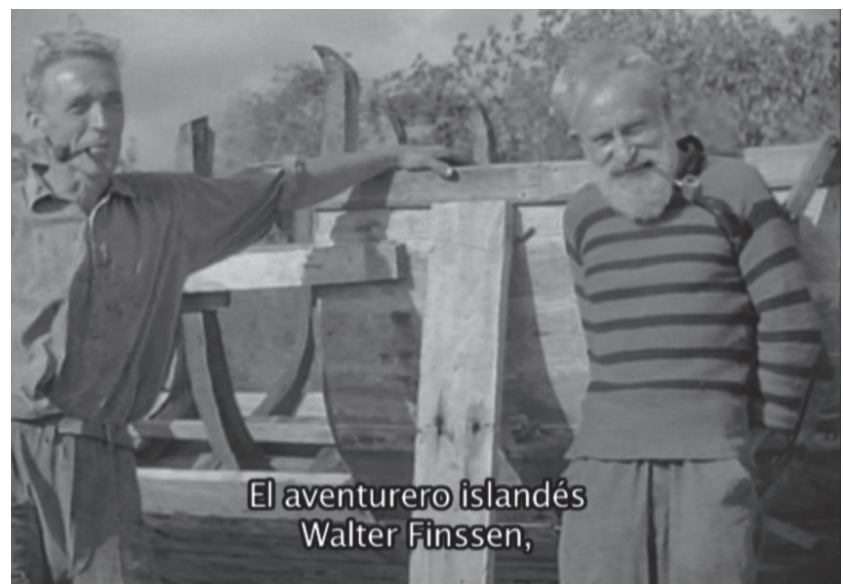

La principal diferencia entre ambas películas se da desde el discurso. En la película filmada en la Amazonia, Blomberg por momentos marca la "cara oculta" que tienen los indígenas, que es su lado salvaje. Si bien en las imágenes se los muestra sonriendo, nos dice desde el discurso que son crueles. La reducción de cabezas, como rasgo exótico de la comunidad, es el núcleo de la película. La ambigüedad (Muratorio, 1994), en la construcción de la imagen de los shuar, es el concepto central que marca las relaciones de alteridad entre los exploradores y los indígenas. Con este concepto, nos referimos a significados que toma la imagen que Blomberg construye, que pueden ser considerados como contradictorios. Por un lado son "salvajes", "violentos" y por lo tanto moralmente malos, mientras que por el otro tienen destrezas técnicas que sólo ellos pueden tener y son alegres. Creemos que el imaginario de los europeos que describe Anne-Christine Taylor se aproxima muy bien a la imagen que construye Blomberg sobre los Shuar, donde afirma que "se caracteriza esencialmente por la conjunción inquietante de un saber técnico (anatomo-farmacéutico) altamente sofisticado y de una primitividad y barbarie moral extremas" (Taylor, 1994, p. 89). Esto se puede ver claramente cuando la voz en off (autoridad exclusiva del narrador) marca un contrapunto con la imagen. Con esto nos referimos a que mientras desde la imagen vemos un primer plano de un shuar sonriendo a cámara, desde la voz en 
off se destaca que son "crueles" (ver Figura 6). Pero además, la ambigüedad no sólo está entre la imagen y el sonido, sino en el tipo de relación que los forasteros establecieron con la comunidad shuar. Por un lado, en el libro "Acampando entre los Reductores de Cabezas" (1938), escrito por el mismo Blomberg para relatar su viaje, el autor afirma que las relaciones eran empáticas y de confianza. Por otro, en la película, podemos ver como constantemente tanto extranjeros como locales, portan armas de fuego, dando cuenta de una situación de inestabilidad y desconfianza. La alteridad, por lo tanto, queda delimitada en este doble juego, entre valores ambiguos y fluctuantes, donde predomina principalmente el exotismo (ver Figura 7).

\section{Figura 6 \\ Presentación de los Shuar. Fotograma extraído de "En Canoa a la Tierra de los Reductores de Cabezas"}

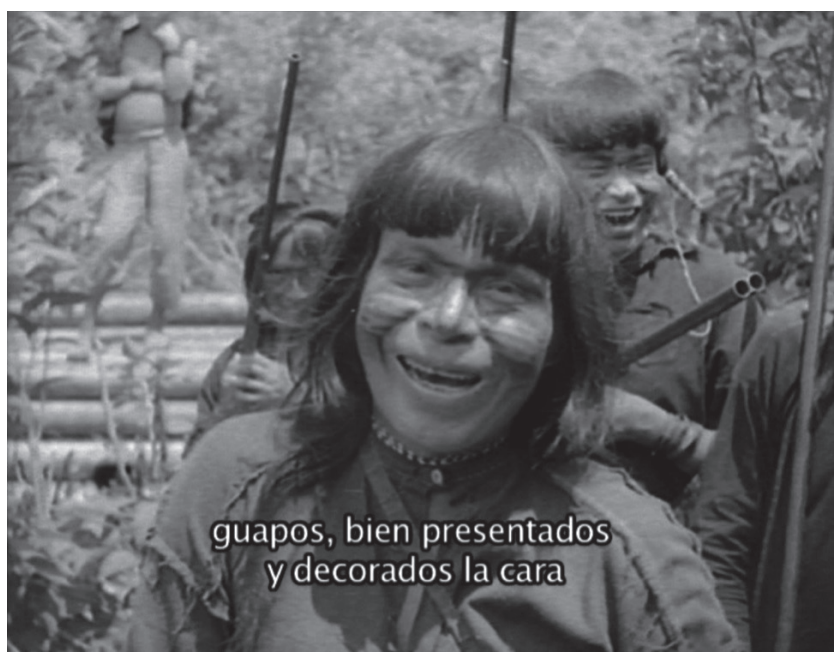

Este es su aspecto: guapos y bien presentados y decorados en la cara y siempre de buen humor. Aunque sonríen a la cámara tienen fama de ser crueles por su espantosa costumbre de cortar la cabeza de las personas. Cogen la cabeza y en un complejo procedimiento la reducen hasta este tamaño. El jíbaro cree que obtiene la fuerza de su enemigo al poseer la cabeza. Y para que no pueda maldecirlo ni murmurar maleficios, le cosen la boca. El que más cabezas ha cortado, tiene el más alto rango social. Pocos blancos han visitado a los reductores de cabezas pero esto no impidió que consiguieran ar- 
mas, camisas y pantalones y otros presentes de la civilización. Pero no siempre han intercambiado estos objetos. Henry nos contó sobre un comerciante quien además de perder sus mercancías también perdió su cabeza (Blomberg 1936, voz en off película "En Canoa a la Tierra de los Cazadores de Cabezas”, Min: 04:24- 05:40).

\section{Figura 7}

\section{Presentación de cabeza reducida fuera de contexto. Fotograma extraído de "En Canoa a la Tierra de los Reductores de Cabezas"}

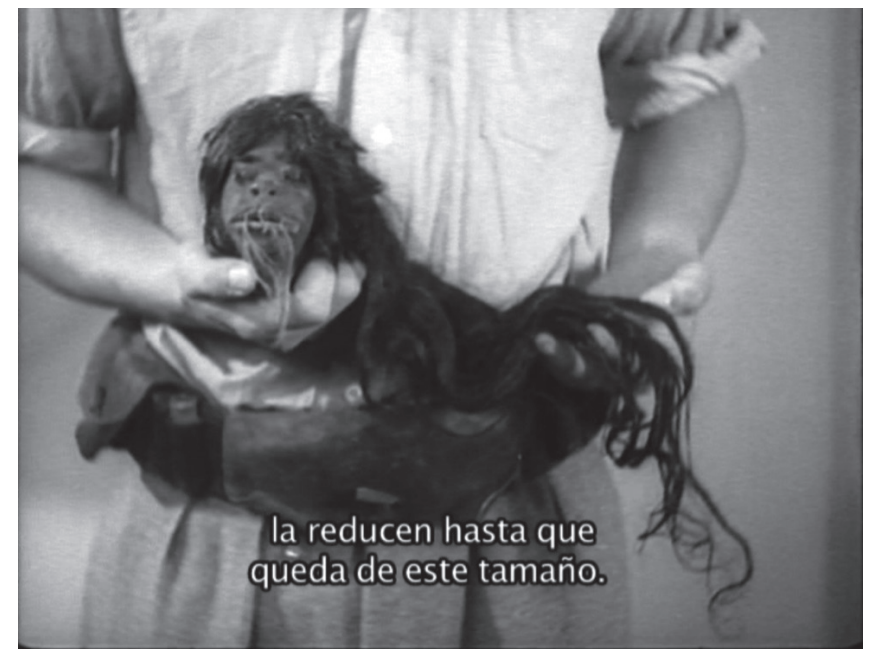

Ahora, si analizamos "Vikingos...", vemos que no hay un doble discurso. Blomberg narra las actividades que realizan los colonos como si él también lo fuese. Si bien nunca utiliza la primera persona para la narración, nos da entender que forma parte de ellos. Lo exótico en esta película es el paisaje y los animales que constituyen un ambiente hostil y salvaje, por lo que los colonos deben desarrollar diferentes estrategias para sobrevivir. A pesar de filmar cacerías de animales, nunca se los nombra como crueles o salvajes a los colonos. En "En canoa..." también se relativizan algunos de los conocimientos, como la construcción de la cerbatana, dándole importancia al conocimiento indígena. Si analizamos esa escena, vemos que fílmicamente se construye de un modo similar a las escenas de "Vikingos...", desde la narrativa clásica. 
La lucha del Hombre contra la Naturaleza lo podemos pensar como un eje en ambas películas. En las dos, se presenta al paisaje como hostil, extraño, exótico, inmenso y deshabitado y es allí donde los grupos locales deben elaborar estrategias para poder sobrevivir. Sin embargo hay una diferencia radical y es que en la película sobre los grupos shuar, se retrata el viaje en canoa hacia el "territorio jíbaro" (como Blomberg lo llama) mientras que en el filme de Galápagos no. Blomberg elige narrar el viaje pero desde un tono dramático (lo mismo se ve reflejado en su libro), dando cuenta de las dificultades y peligrosidades que existía en el recorrido. El desplazamiento espacial de la "civilización" (como Blomberg le llama cuando retornan) a las comunidades indígenas implica atravesar un territorio desconocido y extraño. Sin lugar a dudas que esta idea del espacio amazónico responde a las ideas y los imaginarios de la época, donde el Oriente estaba fuera de la órbita nacional. El paisaje amazónico, inmenso y laberíntico, se remarca desde el discurso pero también desde la elección de los encuadres. Siempre cuando desde la voz en off se habla del paisaje, se eligen planos generales, donde las personas quedan pequeñas en tamaño. Lo dramático del viaje se construye desde lo fílmico, por la utilización de la cámara en movimiento con paneos generales de derecha a izquierda donde personajes se ven pequeños en la inmensidad del paisaje (ver Figura 8). En el relato, Blomberg dice que la canoa "es maniobrada hábilmente por los indígenas, por el río Pastaza, milla tras milla, a través de rápidos y remolinos". Cada vez más alejados de la cámara, se van viendo más pequeños y el paisaje más grande, mientras que la música de tambores y flautas aumenta progresivamente su volumen. La secuencia tiene su clímax cuando la canoa corre peligro, ya que se escapa sola entre los rápidos. Luego del "peligroso" viaje llegan a su objetivo. "Las aguas se hacen más grandes y tranquilas" dice el realizador, mientras que se sigue manteniendo la misma propuesta de cámara: paneos siguiendo la canoa desde planos generales. "Henry ha entrado a la tierra de los jíbaros" dice la voz en off. La imagen se desvanece a un plano negro, la música se corta.

Ahora si analizamos el comienzo de "Vikingos..." la película comienza con un paneo de derecha a izquierda de un plano general de la isla. Dado que el plano tiene una altura aérea, suponemos que fue hecha desde una montaña. El lente que utiliza es un gran angular y esto provoca que las casas se vean pequeñas en un paisaje gigante. Este plano funciona a modo de presentación del paisaje, como extraño, exótico, inmenso y deshabitado. La voz en off, realizada por Blomberg, remarca ese carácter. Allí el realizador 
nos cuenta que vive la colonia escandinava (ver Figura 9). Blomberg ya se encuentra en el lugar al comienzo del filme, no necesita desplazarse fílmicamente. Con respecto a las relaciones de alteridad, hay un Nosotros (escandinavos) que vive en un espacio extraño. El "Nosotros" se construye no sólo por lo que vemos en pantalla, sino por el contexto de circulación en el cual estuvieron las películas. Recordemos que los filmes eran proyectados sólo en Suecia, por lo que los espectadores se veían a "ellos mismos" en la pantalla.

\section{Figura 8}

\section{Presentación del paisaje en la Amazonía} Fotograma extraído de "En Canoa..."

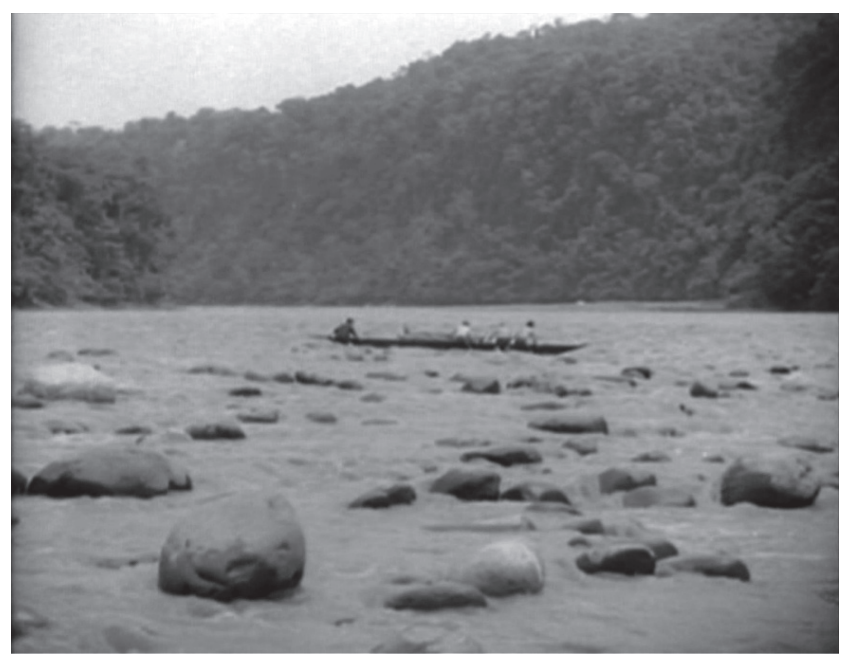

En síntesis, el tiempo y el espacio, características fundamentales del viaje audiovisual, se construyen a partir de la lejanía. Como veíamos, el espacio en ambos filmes se construye como hostil y desolado. Sin embargo el tiempo histórico es diferente. En "En canoa..." la construcción de la lejanía del viaje dramático, hace que también los realizadores se desplacen en el tiempo. Los shuar están ubicados en otro tiempo con respecto a los europeos y ese desplazamiento tiene que ser narrado. Esto se hace notable cuando desde el discurso se marca que "regresan a la civilización". Por el lado de "Vikingos..." el ambiente es lejano y prehistórico, pero los colonos que allí viven no lo son. Blomberg no marca el "retorno a la civilización" en su viaje audiovi- 
sual, simplemente él desde el principio del filme está instalado en la comunidad. Tiempo y espacio se construyen de manera diferente en ambas películas, dando cuenta de la mirada que el realizador tenía con los sujetos filmados.
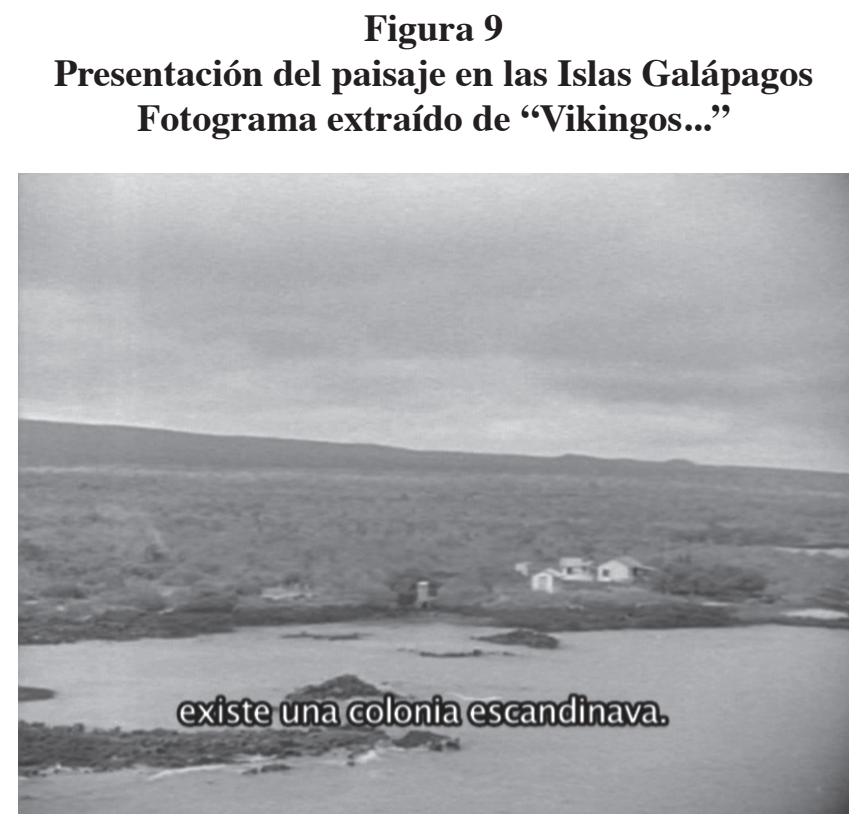

\section{Conclusiones}

Investigar este tipo de imágenes desde los estudios visuales en relación a la Antropología Audiovisual, nos hace pensar en cómo los europeos miran a Ecuador y cómo Ecuador mira a los europeos. Blomberg formó parte de una gama de exploradores- realizadores en todo Sudamérica, pioneros en utilizar la cámara de cine en sus viajes. Es decir, esas primeras imágenes que producían y reproducían, con las ideas traídas de Europa, marcaron un imaginario tanto del territorio insular, como de la sierra, de la costa y de la selva ecuatoriana, que vale la pena seguir investigando. Además, a modo de hipótesis para futuras investigaciones, el trabajo propone que estos mismos imaginarios y formas de representaciones, continúan hasta hoy en día y nos marcan la manera de ver los grupos indígenas y los espacios alejados de las grandes capitales. 
Por último, pretendemos continuar con los estudios sobre la obra de Rolf Blomberg, ya que en el Archivo Blomberg existe gran cantidad de material sobre la misma (películas, fotos, cuadernos, diarios de campo, mapas y cartas, entre otras cosas). Pero no sólo nos debemos detener en Blomberg, sino en toda la gama de exploradores, misioneros, etnógrafos, naturalistas y cientistas, que han realizado imágenes- movimiento de Ecuador. Por lo tanto, se trata de analizar en profundidad, en el cruce entre concepciones antropológicas y visuales, las historias de sus viajes y sus miradas para seguir abriendo nuevos debates en torno a la Antropología Audiovisual ecuatoriana.

\section{Bibliografía}

Ardèvol, E. (2006). La búsqueda de una mirada: antropología visual y cine etnográfico. Barcelona: Editorial UOC.

Aumont, J. \& Michael M. (2006). Diccionario teórico y crítico del cine. Buenos Aires: La Marca.

Blomberg, R. (1936). Hombres diferentes y animales extraños. Caminatas por la Amazonía y Galápagos. Traducido por Marcela Blomberg. Estocolmo: Gebers.

Blomberg, R. (1938). Acampando entre los cazadores de cabezas. Traducido por Marcela Blomberg. Estocolmo: Gebers.

Bordwell, D. \& Thompson, K. (1993). El arte cinematográfico. Barcelona: Paidós. Bordwell, D. (1996). La narración en el cine de ficción. Madrid: Paidós.

Clifford, J. (1999). Dilemas de la cultura: antropología, literatura, y arte en la perspectiva posmoderna. Barcelona: Gedisa.

Cook, P. (1994). The Cinema Book. Reino Unido: British Film Institute.

Giordano M. \& Gustavsson A. (2013). Entre la narrativa de viaje y el discurso antropológico. La primera filmografía en el imaginario del indígena chaqueño. En M. Giordano, L. Sudar Klappenbach y R. Isler Duprat (Ed.), Memoria e imaginario en el nordeste argentino (pp. 23-49). Argentina: Prehistoria.

Griffiths, A. (2002). Wondrous difference: cinema anthropology, \& turn-of the century visual culture. New York: Columbia University Press.

Guarín Martínez, O. (2012). La Amazonía en sus imaginarios cinematográficos: 19141955. Apuntes preliminares. En M. Hering Torres y A. C. Pérez Benavidez (Ed.), Historia Cultural desde Colombia: categorías y debates (pp. 165192). Bogotá: Universidad Nacional de Colombia, Facultad de Ciencias Humanas, Pontificia Universidad Javeriana y Universidad de los Andes. 
Metz, C. (2002). Ensayos sobre la significación en el cine. Barcelona: Ediciones Paidós Ibérica.

Nichols, B. (1997). La representación de la realidad: cuestiones y conceptos sobre el documental. Madrid: Paidós.

Ortega, M. L. (2003). El descubrimiento de América Latina por los documentalistas viajeros. En P. A. Paranaguá (Ed.), Cine documental en América Latina. España: Cátedra.

Rony, F. T. (1996). The third eye: race, cinema, and ethnographic spectacle. Durham: Duke University Press.

Suhr, C. y Willerslev, R. (2012). Can Film Show the Invisible? The Work of Montage in Ethnographic Filmmaking. Current Anthropology, 53(3).

Taylor, A-C. (1994). Una categoría irreductible en el conjunto de las naciones indígenas: los Jívaro en las representaciones occidentales. En B. Muratorio (Ed.), Imágenes e imagineros (pp. 75-106). Quito: FLACSO.

Fecha de recepción: 19/06/2017; fecha de aceptación: 25/07/2017;

fecha de publicación: 01/09/2017 